Saudi Journal of Medical and Pharmaceutical Sciences

Abbreviated Key Title: Saudi J Med Pharm Sci

ISSN 2413-4929 (Print) | ISSN 2413-4910 (Online)

Scholars Middle East Publishers, Dubai, United Arab Emirates

Journal homepage: https://saudijournals.com

\title{
Epidemiological and Therapeutic Profile of Leishmaniasis in the Province of Al Haouz-Morocco
}

Fatima Zahrae Lazrak ${ }^{1 *}$, Ait Antar Doha ${ }^{1}$, Mina Bezaze ${ }^{2}$, Mustapha Jader ${ }^{2}$, M. Sbai ${ }^{1}$, Redouane Moutaj ${ }^{1}$, El Mostafa El Mezouari $^{1}$

${ }^{1}$ Parasitology-Mycology Laboratory, Avicenna Military hospital. Faculty of Medicine and Pharmacy, Cadi Ayyad University, Marrakesh, Morocco

${ }^{2}$ Provincial health delegation from Al Haouz, Marrakesh, Morocco

DOI: $10.36348 /$ sjmps.2022.v08i01.002

| Received: 13.11.2021 | Accepted: 18.12.2021 | Published: 10.01.2022

*Corresponding author: Fatima Zahrae Lazrak

\section{Abstract}

The objectives of our study are to trace the epidemiological profile of cutaneous and visceral leishmaniasis in the province of al Haouz and to study the effectiveness of the national control program against leishmaniasis in this endemic area. It is a descriptive epidemiological study of cases recorded in public health facilities (health centers) and in the service of infrastructure and provincial ambulatory activities (SIAAP) of the province al Haouz between 2015 and 2019. Also it is an evaluative study of the provincial leishmaniasis control program. We found 264 cases of CL (94.96\%) and 14 cases of VL (5.03\%). The age groups most affected by CL were $0-5$ years and pediatric cases (age less than 15 years) represented 74.62 percent of all CL cases. Females accounted for 61.15 percent of CL cases. The evolution of the number of notified cases of CL each year showed significant variations with a minimum value of 36 in 2015 and a maximum value of 70 in 2018 with an average number of CL cases recorded per year of 52 cases. The period at risk of CL contamination was the second and third quarter of the year with a percentage of 69.7 percent. 93.18 percent of communes affected by CL were rural communes. Passive screening was 96.59 percent with a number of LC cases of 255 . $248 \mathrm{CL}$ cases $(93.93 \%$ of cases) were treated locally and 2 cases $(0.75 \%)$ were treated systemically. 14 cases of VL were recorded, with a minimum value of 1 case in 2016 and a maximum value of 5 cases in 2017.All cases were treated by general route. In the present study, the analysis of the annual incidence of CL per 100,000 inhabitants showed a clear decrease in this indicator from 4.48 in 2015 to 1.65 in 2019.

Keywords: Leishmania, Leishmania Tropica, Leishmania Infantum, Al Haouz.

Copyright () 2022 The Author(s): This is an open-access article distributed under the terms of the Creative Commons Attribution 4.0 International License (CC BY-NC 4.0) which permits unrestricted use, distribution, and reproduction in any medium for non-commercial use provided the original author and source are credited.

\section{INTRODUCTION}

In all the world, leishmaniasis remains a major health problem in 4 eco-epidemiological regions of the world: the Americas, East Africa, North Africa, and West and South Asia. Est [1]. In Morocco, leishmaniasis disease is a public health problem, it is the first group of vector-borne disease [2].

Our work is a descriptive and evaluative case study carried out from data recorded in public health establishment (health centers) who report their cases to the service of infrastructure and provincial ambulatory activities (SIAAP) of the province of al Haouz during the period between 2015 and 2019. Its objectives are to trace the epidemiological profile of cutaneous and visceral leishmaniasis in the province of al Haouz and to analyze the peculiarities of the province of al Haouz as well as an endemic area of leishmaniasis.

\section{Materials ANd Methods}

\section{Place of study}

Located in the north of Marrakech On an area of $6212 \mathrm{~km} 2$,Al Haouz province is made up of the socalled "Haouz" plain and mountain ranges (74\% of the total area of the province) whose altitude varies between 1000 and 4167 meters (Toubkal the highest point in Morocco). This province is populated by 573,128 inhabitants with an urbanization rate of $14.79 \%$. 


\section{Study Method}

Type and duration of study:

This is a descriptive epidemiological study of the cases recorded in public health establishment (health centers) and in the service of infrastructure and provincial ambulatory activities (SIAAP) of al Haouz province. It is also an evaluative study of the provincial leishmaniasis control program. All cases of cutaneous and visceral leishmaniasis diagnosed by health workers in these health establishment from 2015 to 2019, and notified in these registers, were listed.

\section{Inclusion Criteria:}

The patients included in this study were those who are residents of al Haouz province, whoever the age and gender.

\section{Exclusion Criteria:}

Patients who do not live in the region, cases of leishmaniasis diagnosed outside this study period and cases of leishmaniasis from other provinces who consulted in health establishment in $\mathrm{Al} \mathrm{Haouz} \mathrm{province}$ are excluded from this study.

\section{Data Collection}

The data were collected from registers prepared by the SIAAP from the provincial delegation of the ministry of health of al Haouz province.

The total number of the Al Haouz population was estimated according to the last general population and housing census (High Commission for Planning, 2014).

The results were collected from technical sheets prepared by the Ministry of Health containing epidemiological information. The agreement was taken from the regional directorate of Marrakech-Safi.

The variables studied were: age, sex, annual distribution, quarterly distribution, distribution by municipality, distribution by area (rural or urban) and type of screening (active or passive).

\section{RESULTS}

In our study, the human cases of leishmaniasis were mainly cases of LC and less of VL. We found 264 cases of CL $(94.96 \%)$ and 14 cases of VL (5.03\%) (Figure 1).

Epidemiology of leishmaniasis:

The cases of CL recorded throughout the territory of $\mathrm{Al}$ haouz province during the period from 2015 to 2019 were 264 cases (Figure $2 \& 3$ ).

Analysis of the age distribution of CL cases in Al Haouz province from 2015 to 2019 showed that all ages were affected by the disease with extremes of 1 year to 81 years. The most affected age groups were 0 to 5 years. Pediatric cases (age less than 15 years) accounted for $74.62 \%$ of all CL cases. While the distribution of CL cases between the sexes was unbalanced with a clear predominance of women: $61.15 \%$ of cases, the sex ratio $\mathrm{M} / \mathrm{F}$ was: 0.53 .

At the level of $\mathrm{Al}$ Haouz province, the evolution of the number of cases notified each year has a significant variations with a minimum value of 36 in 2015 and a maximum value of 70 in 2018. The average number of CL cases recorded per year during the period from 2015 to 2019 was 52 cases.

The annual evolution of cutaneous leishmaniasis cases according to the setting of $\mathrm{Al}$ Haouz province during the period of the study shows a very strong predominance of the rural setting which represented about 93,18 .

The incidence of CL per year in the present study increased between 2015 and 2016, then it decreased between 2017 and 2019 with a slight increase in 2018. The maximum value was 5.51 (2016) and the minimum was 1.65 (2019) (Figure 4).

The analysis of the quarterly evolution of CL in $\mathrm{Al} \mathrm{Haouz} \mathrm{province} \mathrm{clearly} \mathrm{showed} \mathrm{the} \mathrm{period} \mathrm{at} \mathrm{risk}$ of contamination, that is the period of the second and third quarter of the year with a percentage of $69.7 \%$ (Table 1).

Passive screening concerns all people who spontaneously go to a health center and in whom the clinical signs of LC will be demonstrated and the smear performed. While active screening is when health workers go out to look for these clinical signs and perform this test. [5]

In the present study, passive screening was largely predominant, it presented $96.59 \%$ with a number of cases of 255 .

Concerning visceral leishmaniasis and during the period from 2015 to 2019,14 cases were recorded, with a minimum value of 1 case in 2016 and a maximum value of 5 cases in 2017 (Figure 1). The incidence per 100,000 inhabitants of LV showed moderate variations with a minimum value of 0.08 (2016) and a maximum of 0.37 (2015).

\section{Therapeutic Aspects:}

248 cases of CL $(93.93 \%$ of cases) received local treatment (Figure 4). The treatment consisted of local disinfection and the use of antibiotic ointment and intra-lesional treatment with meglumine antimony (Glucantime®) at the rate of two injections per week of $2 \mathrm{ml}$ as an average dose for a period of 4 weeks, that is 8 
injections in total. Two patients $(0.75 \%)$ were treated systemically by daily deep intramuscular injection, with a dosage of $20 \mathrm{mg}$ of meglumine antimony / $\mathrm{kg} /$ day for 3 weeks.
14 cases of VL ( $100 \%$ of cases) were treated systemically by daily deep intramuscular injection, with a dosage of $20 \mathrm{mg}$ of meglumine antimony / $\mathrm{kg} /$ day for 3 weeks.

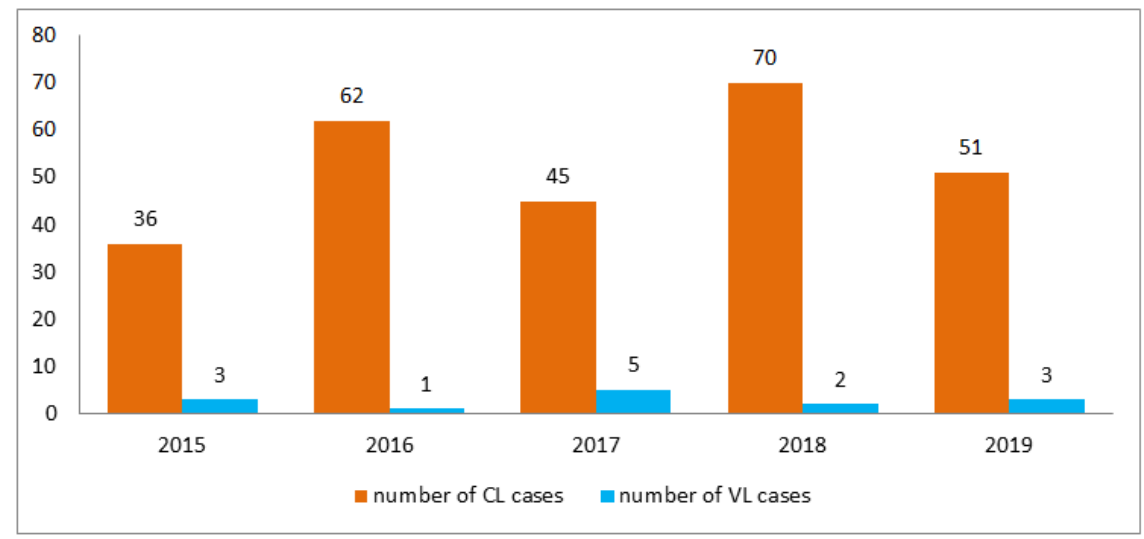

Figure 1: Annual number of CL and VL cases (2015-2019)

Table 1: Quarterly distribution of CL cases by year

\begin{tabular}{|l|l|l|l|l|l|l|}
\hline $\begin{array}{c}\text { Years } \\
\text { Quarter }\end{array}$ & $\mathbf{2 0 1 5}$ & $\mathbf{2 0 1 6}$ & $\mathbf{2 0 1 7}$ & $\mathbf{2 0 1 8}$ & $\mathbf{2 0 1 9}$ & Total per quarter \\
\hline first & 3 & 6 & 7 & 12 & 22 & 50 \\
\hline second & 11 & 17 & 22 & 21 & 14 & 85 \\
\hline third & 18 & 30 & 13 & 28 & 10 & 99 \\
\hline fourth & 4 & 9 & 3 & 9 & 5 & 30 \\
\hline
\end{tabular}

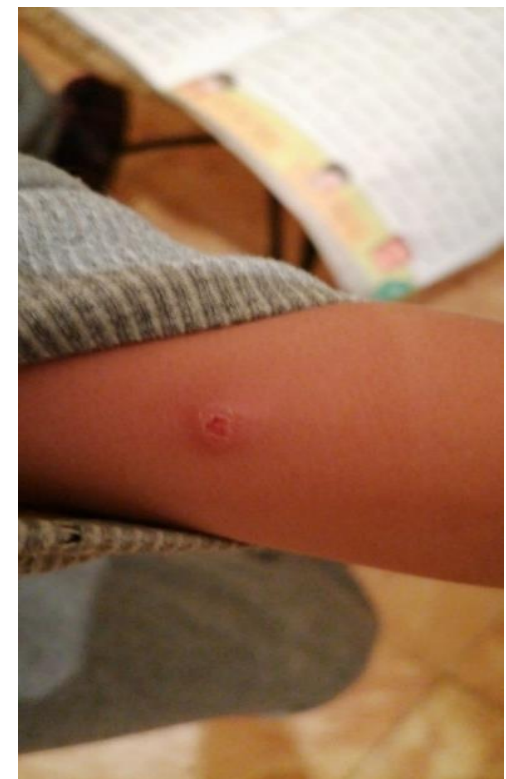

Figure 2: A single small CL lesion

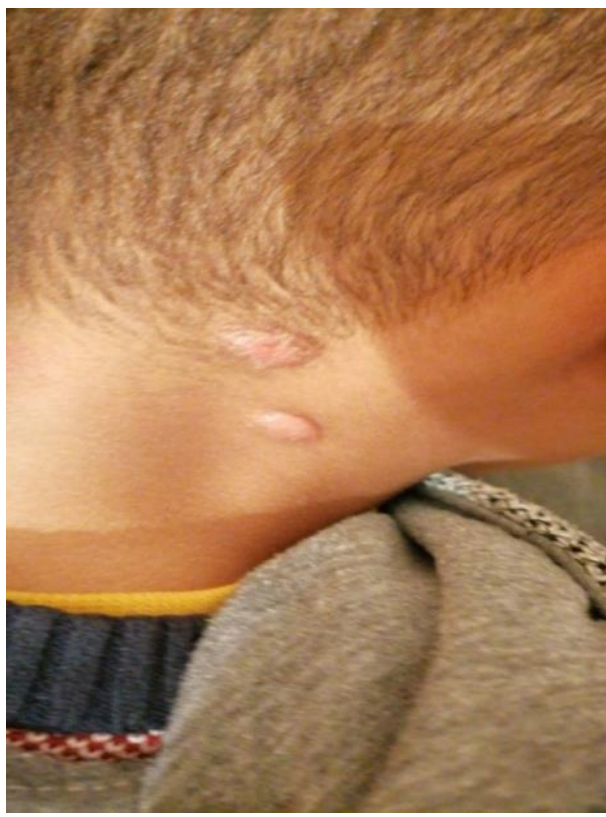

Figure 3: 2 CL lesions in the neck of a child 
Fatima Zahrae Lazrak et al., Saudi J Med Pharm Sci, Jan, 2022; 8(1): 6-11

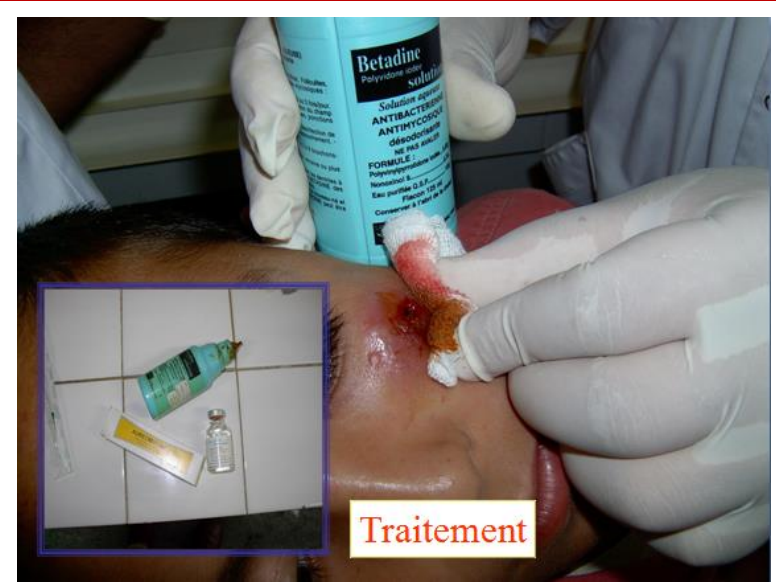

Figure 4: Child receiving local CL treatment in Al Haouz province

\section{DiscuSSION}

Leishmaniasis is a public health problem in Morocco including the Al Haouz region [2]. This identified problem is currently integrated into the priorities of the Ministry of Health. The launch of the leishmaniasis control program in 1997 was the culmination of several years of eco-epidemiological research in the various regions of the country. This research made it possible to identify the leishmaniasis problem and to develop a control strategy translated into a directive aimed at establishing the technical bases of the control program. This program is therefore continuously to respond to the current epidemiological situation which is experiencing not only an extension of transmission areas but also increasing morbidity [2].

Leishmaniases in $\mathrm{Al}$ Haouz province have experienced a course of endemicity over time. Indeed, between 1997 and 2010, 549 cases of CL were recorded with an average value of 40 cases of CL notified per year. In the same period, 18 cases of VL were collected with an average value of 1 case per year.

In our study, the human cases of leishmaniasis were predominantly cases of CL and less of VL. We found 264 cases of CL $(94.96 \%)$ and 14 cases of VL $(5.03 \%)$.

The evolution of $\mathrm{LC}$ in $\mathrm{Al}$ haouz province is characterized by three distinct phases: A first phase from 1997 to 2000: the number of CL cases collected per year is stable with the registration of one case per year.

A second phase from 2001 to 2006: the number of cases of CL increases irregularly. It went from 16 cases in 2001 to 93 cases in 2006 which represents the maximum value of cases notified during the period of 1997 and 2010.
A third phase from 2007 to 2010: the number of cases of CL decreases steadily from 78 cases in 2007 to 30 cases in 2010 .

The annual number of VL cases recorded between 1997 and 2010 in $\mathrm{Al} \mathrm{Haouz} \mathrm{province} \mathrm{is} \mathrm{stable}$ with an average value of 1 case per year.

During the period from 1997 to 2009 , leishmaniasis in $\mathrm{Al} \mathrm{Haouz} \mathrm{province} \mathrm{affects} \mathrm{the} \mathrm{majority}$ of municipalities with a clear predominance at the level of Sittifadma and Ourika municipalities.

Analysis of the age distribution of CL cases in Al haouz province from 2015 to 2019 showed the predominance of pediatric cases (74.62 percent).

This could be explained by the frequent contact of children with the outside environment, so those most exposed to the risk of a sandfly bite. This predominance in children could also be explained by the parents concern for their children and their early consultation before the lesions spontaneously healing or because of the chronicity of the lesions despite several local treatments. In fact, in areas where transmission is very active, the majority of residents are immune. Only children and immigrants are sensitive.

Our result is corroborated with that found by the study conducted at El hajeb which showed that the infant population is the category most affected by this parasitosis with a rate of $61.9 \%$. Thus, infestation by the cutaneous form represented $23.81 \%$ in the 5 to 14 age group and $19.05 \%$ in the 0 to 4 year age group [3]. The results of our study also agree with those of studies done in the Maghreb. According to the Algerian study, children under 10 are the most affected [4]. According to the Tunisian study, children under 5 are the most infested $(34.6 \%)$ [5].

The age group most affected by CL found in our study is closer to that observed in most of the studies conducted (Taza, El hajeb, Ouarzazate and Séfrou). While it is lower than those reported in the Tetouan and Jerada series [6-8].

Conflicting results internationally, between 2017 and 2018, showing that around 50\% of CL cases involved people aged more than 15 years $(53 \%$ in 2017 and $55 \%$ in 2018), $20 \%$ (2017) and 27\% (2018) concerned children aged between 5 and 14 years and $18 \%$ (2017) and $21 \%$ (2018) children aged less than 5 years [2].

Our study showed that both sexes were affected with a clear female predominance $(61.15 \%$ of cases). 
This result is consistent with that of the study conducted in El hajeb which revealed that the female / male sex ratio was 1.1 with a predominance of the female sex in adulthood $[7,8]$.

The predominance of the female sex is also noted in other series carried out in Tetouan, Ouarzazate, Taza and Sefrou [6-8]. Same observation for the Tunisian and Algerian series (sex-ratio = 0.95) [9].

Internationally, conflicting results were reported by the WHO which showed that the distribution of CL cases between the sexes was well balanced: $47 \%$ of cases were women in 2018 (52\% men and $2 \%$ without indication of sex) and $45 \%$ of cases were women in $2017(50 \%$ men and $5 \%$ without indication of sex) [12].

Our study reported that rural municipalities represented approximately $93.18 \%$ of the municipalities affected by cutaneous leishmaniasis.

This finding is consistent with that of the El Hajeb study where $76.47 \%$ of patients are from Nationally, our result matches the studies carried out in Ouarzazate $(70 \%)$ and in Séfrou $(67.6 \%)$ rural origin [7, $8,9]$.

Like the Tunisian study: the incidence in rural areas is $39.2 / 100,000$ inhabitants per year compared to urban areas 19.4/100,000 inhabitants per year. Which is consistent with the results of our work? [9]

Rural areas are a favorable environment for the transmission of the disease Where the inhabitants are unsanitary and their surroundings constitute micro-foci allowing contact between man and the sandfly and assure a favorable conditions for the circulation of the parasite. This explains the predominance of rural origin.

This increase would be explained, on the one hand, by the improvement of mandatory reporting and by the mass screenings conducted in the province in 2017 and 2018 [10, 11]. On the other hand, this result would also be explained by the actual increase in the number of cases. In fact, the rural character of the inhabitants of the province $\mathrm{Al}$ haouz and their sociocultural habits in the management of their living environment (the unhygienic disposal of excreta, open defecation of humans and animals, the presence of black spots where they accumulate garbage and waste) are factors that favor the contamination and infestation by parasitic diseases such as leishmaniasis. Also, the majority of ruralists own dogs since they are very beneficial for guarding the houses and fields, but they are one of the main reservoirs of Leishmania infantum [12-14].
The 2018 peak corroborates with the national epidemiological situation which has seen a significant increase in CL cases in different Moroccan regions and provinces.

Comparing our results with those of the study conducted in El hajeb, we note that the average number of cases collected during our study was very high.

Comparing our results according to the national scale, we find that the average number of cases recorded per year during our study was average.

The average number of cases recorded during our study is close to that of the Algerian study [4]. In contrast, the Tunisian study showed a high number [5].

In the present study, 14 cases of VL were recorded in five years. This is significantly higher compared to the El hajeb study which reported only 4 cases of VL [3].

This could be explained by the population's ignorance of the seriousness of this form of leishmaniasis [15]. Thus, the mass screenings performed in the province are also an additional factor explaining these results.

\section{Conclusion}

At the end of this descriptive study of epidemiological surveillance data concerning all cases diagnosed in the province of $\mathrm{Al} \mathrm{Haouz}$ during the period from 2015 to 2019, we conclude the continued presence of this parasitosis in its two main forms: cutaneous and visceral. The declaration of these new cases in the majority of the communes of the province is in favor of the hypothesis of the propagation of a possible epidemic of this disease.

\section{BibliograPHIE}

1. World Health Organization (WHO). (2020). Weekly epidemiological record, Global leishmaniasis surveillance, 2017-2018, and first report on 5additional indicators, p 265-274.

2. [2] Laamrani el idrissi, A., Lakranbi, M., Bouhout, S., Elabandouni, M., Nhami, H., Ameur, B., Herrak, T., El Hassane, N., Bouhrara, M., Rhajoui, M., Faraj, C., EL Fellah, H., EL Menzhi, O., \& Benmamoun A. (2010). Lutte contre les leishmanioses guide des activité, p 31-32.

3. El-Mouhdi, K., Abdelkader, C., Abdelhakim ElOuali, L., Jawad, B., \& Hajar El, O. (2019). Situation Épidémiologique des Leishmanioses au Niveau de la Ville d'El Hajeb (Centre du Maroc) durant la Période de 2013 à 2017. European Scientific Journal, 15(3), p160-161. 
4. Bachi, F. (2006). The epidemiological and clinical aspect of leishmaniasis in Algeria. p 11-12.

5. Fourati, E. (2012). Enquêtes entomologiques dans un foyer de Leishmaniose cutanée zoonotique du Centre Tunisie: projet de fin d'études en vue de l'obtention de la Licence appliquée en Protection de l'environnement dans la spécialité, Environnement et sécuritaire.

6. Riyad, M., Chiheb, S., \& Bichichi, M. (2006). Evolution de la leishmaniose cutanée à Leishmania tropica au Maroc: l'exemple du foyer de Taza. $J$ Prat, 15(2), 20-25.

7. Rhajaoui, M. (2011). Les leishmanioses humaines au Maroc: une diversité nosogéographique. Pathologie Biologie, 59, 226-229. 25.

8. Guessous-Idrissi, N., Berrag, B., Riyad M., Sahibi, H., Bichichi M., \& Rhalem, A. (1997). Leishmania tropica: etiologic agent of a case of visceralizing canine leishmaniasis in north Morocco. Am J Trop Med \& Hyg, 57, 172-173.

9. Yazoumé, Y., Samantha, H., Tabitha, K., Bolanle, O., Deepa, P., Inessa, B., \& Arnaud, L. M. (2020). Cadre d'évaluation des programmes nationaux de lutte contre le paludisme dans les zones detransmission modérée et faible, p 9-12.

10. World Health Organization (WHO). (2010). La lutte contre les leishmanioses. Rapport de la réunion du comité OMS d'experts de la lutte contre lesleishmanioses, Genève, p 84- 87

11. Savoia, D. (2015). Recent updates and perspectives on leishmaniasis. J Infect Dev Ctries, 9(6), 588596.

12. Kobets, T., Grekov, I., \& Lipoldová, M. (2012). Leishmaniasis: Prevention, Parasite Detection and Treatment. Current Medicinal Chemistry, 19(10), 1443-1474.

13. Pace, D. (2014). Leishmaniasis. Journal of Infection, 69, 10-18.

14. World Health Organization (WHO). (2010). First WHO report on neglected tropical diseases. Working toovercome the global impact of neglected tropical diseases.

15. World Health Organization. (2010). Report of a meeting of the WHO Expert Committee on the Control of Leishmaniases, Geneva. WHO technical report series, 949, 22-26. 